[10] Kim, H., Piao, Z., Park, C., Chung, W., Park, C. (1998). Clinical significance of clonality in thyroid nodules. British Journal of Surgery, 85 (8), 1125-1128. doi: http://doi.org/10.1046/j.1365-2168.1998.00783.x

[11] Studer, H., Gerber, H., Zbaeren, J., Peter, H. J. (1992). Histomorphological and immunohistochemical evidence that human nodular goiters grow by episodic replication of multiple clusters of thyroid follicular cells. Journal of Clinical Endocrinology \& Metabolism, 75 (4), 1151-1158. doi: http://doi.org/10.1210/ jc.75.4.1151

[12] Mitsutake, N., Iwao, A., Nagai, K., Namba, H., Ohtsuru, A., Saenko, V., Yamashita, S. (2007). Characterization of Side Population in Thyroid Cancer Cell Lines: Cancer Stem-Like Cells Are Enriched Partly But Not Exclusively. Endocrinology, 148 (4), 1797-1803. doi: http://doi.org/10.1210/en.2006-1553

[13] Bozhok, Y., Tavokina, L., Epstein, E. (1996). The new things in diagnostic of thyroid cancer. Optimal combination of morphological and immunocytochemistry research methods of punctious materials. Med Announcer, 138, 40-43.

[14] Zelinskaya, A. (2019). Citokeratin 17 i tireoidna peroksidaza v yakosti imunocitohimichnih markeriv dooperaciynogo prognozuvannya radioiodrezistentnosti ta efektivnosti radioiodterapii papilyarnogo raku shitopodibnoi zalozi. Onkologiya, 21 (1), 31-35.

[15] Latza, U., Niedobitek, G., Schwarting, R., Nekarda, H., Stein, H. (1990). Ber-EP4: new monoclonal antibody which distinguishes epithelia from mesothelial. Journal of Clinical Pathology, 43 (3), 213-219. doi: http://doi.org/10.1136/jcp.43.3.213

\title{
IFLUENCE OF AQUEOUS EXTRACT FROM FEIJOA LEAVES ON THYROID FUNCTION IN RATS WITH EXPERIMENTAL HYPOTHYROIDISM
}

\author{
Alevtyna Kononenko \\ Department of Physiology and Human Anatomy \\ National University of Pharmacy \\ 53 Pushkinskaya str., Kharkiv, Ukraine, 61002 \\ alevtina19820103@gmail.com \\ Vera Kravchenko \\ Department of Physiology and Human Anatomy \\ National University of Pharmacy \\ 53 Pushkinskaya str., Kharkiv, Ukraine, 61002 \\ kvn1965@gmail.com
}

\begin{abstract}
The present work studied the effect of aqueous extract from Feijoa leaves on thyroid function of rats with experimental hypothyroidism. Healthy albino rats weighing between $120 \mathrm{~g}$ and $150 \mathrm{~g}$ were used. The animals were randomly allotted into four groups, each containing eight rats respectively. Three of the groups (II, III and IV), induced with hypothyroidism, were treated by $0.05 \%$ solution of thiamazole with drinking water for 30 days. Control (vehicle) rats were given normal saline. After 13 days hypothyroid groups (III and IV) of rats were treated with aqueous extract from Feijoa leaves at a dose $1.0 \mathrm{ml} / 100 \mathrm{~g}$ of body weight and with Iodomarin 200 (reference drug) at a dose $12 \mu \mathrm{g} / \mathrm{kg}$ daily orally for 21 days. Results obtained from the study showed that the introduction of thiamazole leads to functional changes in the thyroid gland in rats, accompanied by decreasing sings of rectal temperature and level of thyroid hormones. It was found, that treatment with AEFL normalizes serum thyroid hormone levels, increases rectal temperature and reduces the thyroid mass. The investigated extract can be attributed to the regulators of the thyroid hypofunction and is promising for further study of its effectiveness as a thyroid-stimulating agent.
\end{abstract}

Keywords: Feijoa leaves, aqueous extract, hypothyroidism, thiamazole, thyroid hormones. 


\section{Introduction}

Increased interest in the problem of thyroid pathology in recent years is due to its distribution among the population, as well as high frequency of temporary and permanent disability, which determines the social significance of diseases [1,2]. Thus, in the structure of endocrine diseases, one of the main places belongs to the pathology of the thyroid gland, which is $47.3 \%[1,3]$.

The increase in the frequency of thyroid pathology is due to the influence of adverse environmental factors, the deterioration of the overall ecological situation, which contribute to reducing the immunological defense of the body, as well as defective food and stress factors [2, 4].

Hypothyroidism is one of the most common thyroid diseases. According to some epidemiological studies in some population groups, the prevalence of hypothyroidism reaches $10-12 \%$ and is constantly increasing. In adults, it is in the range of 1.4 to $2 \%$ for women and $0.2 \%$ for men. The greatest incidence of hypothyroidism is observed in the age group over 60 years. Thus, among the surveyed (without thyroid diseases in past medical history), the percentage of patients with hypothyroidism reaches $6 \%$ among women and $2.5 \%$ in men. The incidence of hypothyroidism in children is 1: 3000-4000 [1].

For the treatment of hypothyroid states, substitution therapy - thyroid hormones - is mainly used, or therapy aimed at restoring the deficit of iodine-Iodine preparations $[4,5]$. However, pharmaceutical correction with the help of drugs of chemical origin is not always sufficiently effective, convenient in use, and can cause side effects with long-term treatment. Today, herbal products occupy the essential part of both the European and world pharmaceutical market: according to various estimates, this share is $30-50 \%[6,7]$. Phytotherapy is used in combination with pharmaceutical treatment or independently in mild forms of the disease, between the courses of medical treatment, as well as for prevention.

In folk medicine, various medicinal plants are often used, such as brown and red algae, laminaria saccharidae, aconite Baikal, Icelandic moss, feijoa, fucus and others for both prevention and treatment of thyroid diseases. Of interest are also the results of the application of biologically active additives of herbal origin in thyroid pathology. However, application of herbal remedies containing herbal mixtures does not always give the expected clinical effect, which may be due to the antagonism of the constituent substances, their low concentration or other reasons $[8,9]$.

The uniformity of dosage forms, the prevalence of imported manufacturers and the lack of herbal preparations characterize the pharmaceutical market for thyroid drugs in Ukraine [7]. In this regard, the considerable interest of scientists in finding new safe and effective medicines capable of preventing and correcting thyroid function disorders is justified. The most promising source of biologically active substances of thyrotrophic action is medicinal plants.

One of the promising plants for the prevention and treatment of hypothyroidism are feijoa leaves. Phytochemical studies of feijoa leaves revealed iodine and 14 other elements (calcium, potassium, silicon, sodium, etc.). Thirty-two biological active substances of various chemical groups (phytosterols, saturated hydrocarbons, aldehydes and ketones, fatty acids, etc.) were identified [6]. The results of our previous screening studies in healthy rats showed the thyroid stimulating effect of feijoa leaves in the form of aqueous extract [10].

Therefore, the aim of the research was to detect the influence of aqueous extract from Feijoa leaves on the thyroid function at experimental hypothyroidism.

\section{Materials and Methods}

Aqueous extract from Feijoa leaves was obtained at the Department of Quality, Standardization and Certification of drugs (National University of Pharmacy) and standardized in accordance with the requirements of the State Pharmacopoeia of Ukrainian and European Pharmacopoeia [11]. Thiamazole was obtained at LLC "PC “Zdorov'ya” (Kharkov, Ukraine). Iodomarin 200 (Berlin-Chemie AG/Menarini Group, Germany) was obtained commercially.

\section{1. Experimental Animals}

Thirty-two albino male rats weighing between 120 to $150 \mathrm{~g}$ were obtained and housed in the Central Scientific Research Laboratory, National University of Pharmacy, Ukraine. The normal 
standard rat chow and tap water were provided ad libitum during the experiment. Animals were stabilized to acclimatize to the animal house environment for one week before commencement of the experiment. The study protocol was approved by Bioethics Commission of the National University of Pharmacy and the "General ethical animal experimentation" (Kyiv, 2001), consistent with the provisions of the European Convention for the Protection of Vertebrate Animals, used for Experimental and Other Scientific Purposes (Strasbourg, 1986).

\section{2. Experimental procedures}

\section{2. 1. Induction of Hypothyroidism}

Experimental hypothyroidism was induced by thiamazole in distilled drinking water (500 mg per liter) for 30 days. Control (vehicle) rats were received equal volume of drinking water [12]. Thirteen days after introduction of thiamazole treatment of animals was starting.

\section{2. 2. Experimental Design}

Normal healthy rats were used as normal control and hypothyroidism-induced rats were studied, they all were randomly allotted into four groups $(n=8)$ :

Group 1: Normal untreated rats were given normal saline $1 \mathrm{ml} / 100 \mathrm{~g}$ of body weight daily orally for 21 days.

Group 2: Hypothyroid untreated rats were given normal saline $1 \mathrm{ml} / 100 \mathrm{~g}$ of body weight daily orally for 21 days.

Group 3: Hypothyroid rats were treated with aqueous extract from Feijoa leaves $1 \mathrm{ml} / 100 \mathrm{~g}$ of body weight daily orally for 21 days.

Group 4: Hypothyroid rats were treated with Iodomarin $20012 \mu \mathrm{g} / \mathrm{kg}$ daily orally for 21 days.

\section{2. 3. Body temperature, body mass and thyroid hormones analysis}

At the 12th, 19th, 26th and 34th day of the experiment, experimental animals were weighed. At day 33 rectal temperature was measured, which was recorded at $7^{00}, 11^{00}, 15^{00}, 19^{00}, 23^{00}$ and $7^{00}$ using an electronic thermometer.

At the end of the study period, the animals were withdrawn from the experiment by instantaneous decapitation under thiopental anesthesia $(20 \mathrm{mg} / \mathrm{kg})$, blood was collected, thyroid gland removed and weighed. In blood serum, the concentration of iodine-containing thyroid hormones - triiodothyronine (T3) and thyroxine (T4) was determined by immunoassay analysis using test systems (LLC “Hema”, Russia).

\section{3 Statistical Analysis}

All data were expressed as Mean \pm SEM and data were entered and analyzed using statistical package «Statistica 6.0» with multiple comparisons. The Newman-Keylsa test was used to determine difference between groups. Values of $\mathrm{P}<0.05$ were considered as statistically significant $[5,8]$.

\section{Results and discussion}

The results of the study, presented in Table 1, showed that the use of thyreostatics had led to changes in the body weight of experimental animals. At day 12 of the experiment in animals of the hypothyroid group and animals of group 3-4, body weight gain was increased by $26.6 \%$ on average, and body mass gain in the animals of the control group was $35 \%$ of the baseline. At the end of the experiment (34th day), the body weight of the rats of the hypothyroid group was less than that of control rats by $41 \%$ (Table 1). Such a phenomenon may be a manifestation of inadequate thyroid hormones and somatotrophic hormone in young animals. It is believed that, along with the deficiency of thyroxin and triiodothyronine, a deficiency of somatotrophic hormone, which secretion is due to thyroid hormones, develops [13]. Losing weight in animals may also be associated with a decrease in the appetite of experimental animals and, as a result, a decrease for food consumed. 
Table 1

Dynamics of body mass of rats (g) during the experiment

\begin{tabular}{cccccc}
\hline \multirow{2}{*}{ Group } & \multicolumn{5}{c}{ Experiment days } \\
\cline { 2 - 6 } & 0th & 12th & 19th & 26th & 34th \\
\hline Control & $125.00 \pm 3.27$ & $160.00 \pm 5.35$ & $173.80 \pm 5.32$ & $188.13 \pm 5.34$ & $210.63 \pm 6.01$ \\
Hypothyroid & $128.13 \pm 3.27$ & $156.25 \pm 3.75$ & $162.50 \pm 3.78$ & $168.13 \pm 5.51^{*}$ & $175.50 \pm 6.34^{*}$ \\
TreatedwithAEFL & $127.50 \pm 4.82$ & $152.50 \pm 5.90$ & $160.00 \pm 6.05$ & $173.75 \pm 6.67$ & $184.38 \pm 6.37^{*}$ \\
$\begin{array}{c}\text { Treated with } \\
\text { Iodomarin }\end{array}$ & $121.88 \pm 5.26$ & $148.13 \pm 3.53$ & $154.38 \pm 4.38$ & $163.13 \pm 3.53^{*}$ & $172.5 \pm 4.63^{*} * *$
\end{tabular}

Note: AEDF - aqueous extract from Feijoa leaves; Values are mean $\pm S E M, n=8 ; *-P<0.05$ versus control group; ** $-P<0.05$ versus hypothyroid group

In the weighing of thyroid in the hypothyroid group, an increase in its size and an increase in its mass in 3 times as compared to the control group was revealed, indicating that there was a goiterogenic effect on thiamazole (Table 2).

In the group of hypothyroid animals, treated with AEFL, the body weight gain at the end of the trial was $61.3 \%$ versus $85.6 \%$ in the control group. In the experimental group of animals receiving the reference drug Iodomarin, the ultimate body weight of the rats was lower than that of the control group, but greater than that of the hypothyroid group (Table 1).

Treatment with AEFL resulted in a possible reduction in the size of the thyroid and its mass by 1.4 times compared with the hypothyroid group, indicating the presence of an antigoiterogenic effect in the test extract. The use of the reference drug also prevented the development of the goiterogenic effect of thiamazole, but the rashes to a lesser degree than AEFL. Thus, Iodomarin reduced the mass of the thyroid gland by 1.3 times compared with the hypothyroid group (Table 2).

The development of the hypothyroid state is also confirmed by changes in rectal temperature in rats receiving thiamazole, which was manifested by its steady decrease in all phases of the temperature rhythm by an average of $1.5^{\circ} \mathrm{C}$ compared with the control group (Fig. 1). The introduction of AEFL on the 21st day led to a statistically significant increase in the rectal temperature in all phases of the daily rhythm to the level of the control group. The reference drug Iodomarin also led to the restoration of temperature indices, but somewhat inferior to the investigated extract (Fig. 1).

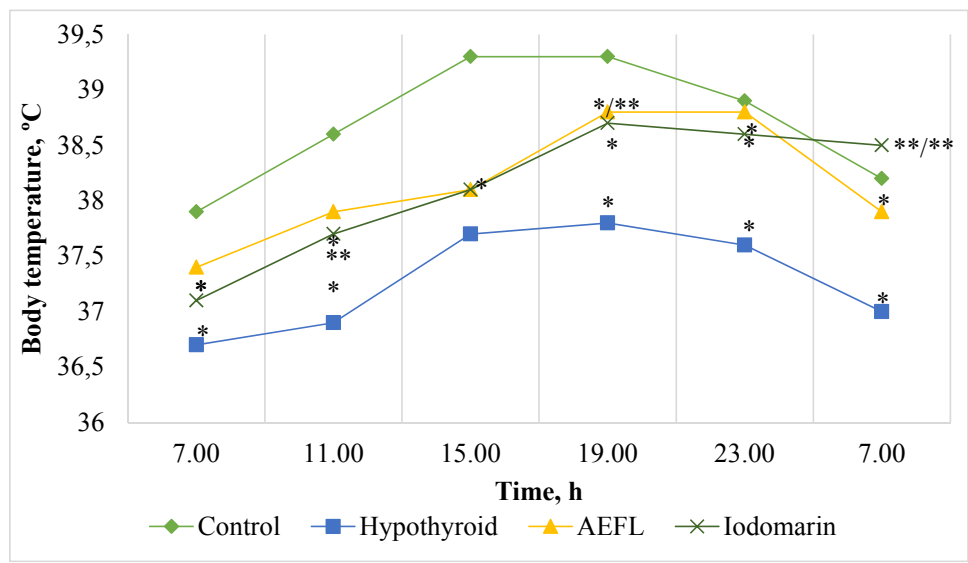

Fig. 1. Curve of daily rhythms of body temperature of rats: AEFL - aqueous extract from Feijoa leaves; Values are mean \pm SEM, $n=8$; * $-\mathrm{P}<0.05$ versus control group; ** $-\mathrm{P}<0.05$ versus hypothyroid group

The use of thiamazole resulted in a decrease in the synthetic thyroid function, which was manifested in decreasing the level of thyroid hormones. Thyroxin and triiodothyronine were sta- 
tistically significantly lower than in control animals by 1.9 and 1.5 times, respectively (Table 2). The course administration of AEFL contributed to the normalization of the functional state of the thyroid gland and the enhancement of its synthetic function, which manifested in a probable increase in T4 and T3 levels by 1.5 and 1.3 times, respectively, compared with the hypothyroid group. It should be noted, that the effect on the thyroid hormones content exceeded the effect of the Iodomarine, which resulted in a probable increase in the T4 and T3 content in comparison with the hypothyroid group by 1.3 and 1.2 times, respectively (Table 2 ).

Table 2

Concentration of thyroid hormones (T3, T4) in blood serum of experimental rats $(n=8)$

\begin{tabular}{ccccc}
\hline Indicator & Control & Hypothyroid & Treated with AEFL & Treated with Iodomarin \\
\hline Thyroid gland mass, mg & $15.63 \pm 0.68$ & $48.63 \pm 2.99 *$ & $36.63 \pm 0.99 * / * *$ & $38.71 \pm 1.91 * / * *$ \\
$\mathrm{~T}_{3}, \mathrm{nmol} / 1$ & $2.33 \pm 0.16$ & $1.50 \pm 0.13^{*}$ & $1.95 \pm 0.10^{* *}$ & $1.83 \pm 0.11 *$ \\
$\mathrm{~T}_{4}, \mathrm{nmol} / 1$ & $61.54 \pm 3.82$ & $26.56 \pm 0.99 *$ & $43.18 \pm 2.81 * / * *$ & $35.40 \pm 1.97 * / * *$
\end{tabular}

Note: AEDF-aqueous extract from Feijoa leaves; Values are mean $\pm S E M ; *{ }_{-}-P<0.05$ versus control group; ** $-P<0.05$ versus hypothyroid group

The results of this study indicate the effectiveness of AEFL in thyroid hypofunction. However, the obtained data do not allow describing the mechanism of action of the studied extract in experimental hypothyroidism. It is possible to assume, that the positive effect of AEFL on the synthetic function of the thyroid gland is realized due to its effect on the enzyme systems that are involved in the processes of synthesis, deiodination and protein binding of thyroid hormones.

In addition, the analysis of literature data and the results of the work of other scientists in the field of the use of plant substances for the correction of hypothyroidism did not reveal similar studies on Feijoa leaves. In the available literature, there are data on the use of fresh Feijoa fruit in the treatment of hypothyroidism as a means of folk medicine [14].

Therefore, based on the above, it can be concluded, that AEFL is promising for further research and studying the mechanisms of its influence on the functional activity of the thyroid gland as a thyroid-stimulating agent.

\section{Conclusions}

1. Introduction of thiamazole markedly inhibits the functional activity of the thyroid gland in rats, causing rectal temperature reduction and decrease of the thyroxine and triiodothyronine content in serum of experimental animals.

2. Treatment with AEFL had a corrective effect on the hypofunction of the thyroid gland, as evidenced by an increase in rectal temperature, a decrease in goiterogenic action of thiamazole and a possible increase in the level of thyroid hormones in serum of experimental animals.

3. The Feijoa leaves extract can be attributed to thyroid hypofunction regulators and is promising for further study of its efficacy in other models of experimental hypothyroidism as a thyroid-stimulating agent.

\section{Acknowledgments}

The authors wish to thank the Central Scientific Research Laboratory staff of the National University of Pharmacy for the care of the experimental animals throughout the period of this research work.

\section{References}

[1] Kravchenko, V. I., Postol, S. V. (2011). The dynamics of morbidity in pathology of thyroid gland in Ukraine. International Endocrinological Journal, 3 (35), 26-31. 
[2] Bajaj, J. K., Salwan, P., Salwan, S. (2016). Various possible toxicants involved in thyroid dysfunction: A Review. Journal of Clinical and Diagnostic Research, 10 (1), FE01-FE03. doi: http://doi.org/10.7860/ jcdr/2016/15195.7092

[3] Mangge, H., Becker, K., Fuchs, D., Gostner, J. M. (2014). Antioxidants, inflammation and cardiovascular disease. World Journal of Cardiology, 6 (6), 462-477. doi: http://doi.org/10.4330/wjc.v6.i6.462

[4] Javed, Z., Sathyapalan, T. (2015). Levothyroxine treatment of mild subclinical hypothyroidism: a review of potential risks and benefits. Therapeutic Advances in Endocrinology and Metabolism, 7 (1), 12-23. doi: http://doi.org/10.1177/2042018815616543

[5] Volkov, V. P. (2014). A new approach to the evaluation of the morphofunctional state of the endocrine glands. Universum: Medicine and pharmacology, 9 (10). Available at: http://7universum.com/en/ med/archive/item/1589

[6] Vladymyrova, I. N. (2014). Standardization of Approaches to the Purposeful Search of Herbal Medicines for the Treatment of Thyroid Diseases. Kharkiv, 44.

[7] Vladymyrova, I. N., Georgiyants, V. A. (2010). Analytical review of modern thyrotropic drugs. Pharmaceutical bulletin, 4, 90-93.

[8] Lobanov, K. A., Korsun, V. F., Korsun, E. V. (2019). Phytotherapy of hypothyroidism in the elderly. Available at: http://fito-news.ru/terapii/fitoterapiya/9035-fitoterapiya-gipotireoza-v-pozhilom-vozraste. html Last accessed: 13.04.2016

[9] Kiselyova, I. A., Tyoplaya, E. V., Kaminskiy, A. V. (2012). Application of the herbal preparation "Alba" in the treatment of patients with pathology of the thyroid gland. Medical case, 8, 108-119.

[10] Kononenko, A. G., Kravchenko, V. M. (2016). Study of the influence of aqueous extract and tinctures of feijoa leaves on the synthetic thyroid gland function in rats. Bulletin of problems in biology and medicine, 2 (130), 151-154.

[11] Glants, S. (1999). Mediko-biologicheskay statistica. Moscow: Practika, 459.

[12] Karpenko, N. O., Kravchenko, V. M., Orlova, V. O., Shcherbak, O. A., Korenieva, Y. M., Kononenko, A. H. (2016). Pat. 109608 UA. A modeling technique of experimental hypothyroidism in laboratory animals. MPK: A61K 31/00, G09B 23/28, A61P 5/14, A61K 9/08. No. u 2016 02673; declareted: 17.03.2016; published: 25.08.2016, Bul. No. 16.

[13] Ahmetov, A. S., Doskina, E. V. (2010). Akromegalia i gigantism, Moscow: Geotar-Media, 21.

[14] Keles, H., Ince, S., Küçükkurt, I., Tatli, I. I., Akkol, E. K., Kahraman, C., \& Demirel, H. H. (2011). The effects ofFeijoa sellowianafruits on the antioxidant defense system, lipid peroxidation, and tissue morphology in rats. Pharmaceutical Biology, 50 (3), 318-325. doi: http://doi.org/10.3109/13880209. 2011.608074 